\title{
The Help-seeking from Social Capitals and Self-regulated Learning among Pre-service Teachers
}

\author{
Shih-Hsiung Liu ${ }^{1}$ \\ ${ }^{1}$ Center for Teacher Education, National Changhua University of Education, Taiwan \\ Correspondence: Shih-Hsiung Liu, Center for Teacher Education, National Changhua University of Education, \\ No.1, Jin-De Road, Changhua, Taiwan. Tel: 886-4-723-2105. E-mail: shsiung@cc.ncue.edu.tw
}

Received: February 6, 2016

Accepted: February 25, 2016 Online Published: March 18, 2016

doi:10.5539/ass.v12n4p171

URL: http://dx.doi.org/10.5539/ass.v12n4p171

\begin{abstract}
This study aims to investigate the help-seeking subjects for pre-service teachers in need of suggestions for practicum and to determine the prediction of pre-service teachers' social capitals for help-seeking on their self-efficacy for help-seeking and self-regulated learning. A total of 223 pre-service teachers, from a teacher education university at the middle of Taiwan, were invited to fill in the validated questionnaire in October 2015. The analytical results of this study by Chi-square Test achieve significant differences in the five types of help-seeking subjects for the pre-service teachers in need of suggestions for practicum. Another finding of this study by multiple regression analysis indicates that the scores of seeking help from faculties in practicum school and peer interns in practicum school can jointly predict self-efficacy for help-seeking This study concludes that the pre-service teachers preferred seeking help from family members, faculties in practicum school, classmates at university and peer interns in practicum school to university professors. Moreover, pre-service teachers perceived self-efficacy for help-seeking and self-regulated learning when seeking help from faculties and peer interns in practicum schools. Interestingly, peer interns in practicum school are considered as bonding social capital but maybe play a role of suggestion-provider, similar to bridging social capital during the practicum.
\end{abstract}

Keywords: social capital, help-seeking, self-regulated learning, pre-service teachers

\section{Introduction}

Field-based school experiences benefit pre-service teachers in equipping with abilities to teach. However, possible problematic cases during practicum are inevitable. Veeman (1984) indicated that certain problems focused on three facets, i.e., student (e.g, dealing with problems of individual students), material (e.g, insufficient and/or inadequate teaching materials and supplies), and parents (e.g, unable to build positive relationships with parents). Additionally, Huang and Waxman (2009) identified that pre-service teachers perceived a large gap between expected ideal practicum situation and realistic practicum school environment when they engaged in field-based school experiences. Sariçoban (2010) determined that pre-service teachers lack supports in materials and equipment. The problems in field-based school experiences are complicated and often accidentally happen. Pre-service teachers find it hard to deal with the problems with the obtained knowledge acquired from teacher education institutes previously. Furthermore, the potential failure of the problem-solving process may bring pre-service teachers great psychological frustration.

When pre-service teachers create psychological frustration in field-based school practicum, they may seek help from faculties in field-based school. Mentor teachers are always the subjects to be sought for consultation by pre-service teachers. In addition to certain teaching skills, a mentor should provide their pre-service teachers with emotional and psychological support (Rippon \& Martin, 2006). The emotional support benefits pre-service teachers to enhance the confidence in teaching and to increase satisfaction on educational works (Bullough, 2005; Marable, \& Raimondi, 2007). However, mentor teachers do not always succeed in finding an adequate combination of emotional support and task assistance for pre-service teachers (Crasborn \& Hennissen, 2010). Notably, studies have indicated that mentor teachers do not necessarily have sufficient consulting competence (Rodgers \& Keil, 2007) and passion for consulting (Graham, 2006). A study by Liu (2014) further found that person-oriented supports like giving emotional supports seem to be unusually used by excellent mentor teachers. Therefore, pre-service teachers maybe begin to seek help from personals outside of the practicum school.

Help-seeking is often considered as a mechanism of support for depression and suicide prevention in the field of 
mental health (Leavey, Rothi, \& Paul, 2011; Lindsey, Joe, \& Nebbitt, 2010). However, help-seeking had also been used to investigate the social support of students from parents, peers, and teachers and to predict a host of emotional and behavioral adjustments (Malecki \& Demaray, 2003; Wenz-Gross \& Siperstein, 1998). Ryan, Pintrich, and Midgley (2001) identified the four steps in the help-seeking process: become aware of need of help, decide to seek help, identify potential helper(s), and use strategies to elicit help. In terms of the potential helper(s), when pre-service teachers cannot obtain sufficient supports for solving problems during practicum, they may contact their parents, previous classmates and professors at teacher education institutes, and knowledgeable friends.

Putnam (2000) proposed two distinctive types of social capitals for help-seeking: bonding social capital and bridging social capital. Bonding social capital refers to the connections between family and close friends. These people often share similar background sand usually provide emotional supports to each other. In contrast, bridging social capital, involving relatively weak-tie relationships between people from different backgrounds (Williams, 2006), may provide useful task suggestions or new perspectives but typically not emotional support (Granovetter, 1983).

Karabenick and Knapp (1991) proposed two categories of help-seeking for students: formal help-seeking (e.g., from school-provided instructional supports, instructors or teacher assistants) and informal help-seeking (e.g., from peers or knowledgeable friends). However, Karabenick and Knapp also indicated that the majority of college students failed to seek help, particularly through formal channels. Maybe the reason involves psychological factors such as academic self-efficacy, threat to self-esteem, and social embarrassment (Karabenick, 1998; Newman \& Goldin, 1990). The formal help-seeking from school-provided supports (e.g., teachers, administrative services) can offer more useful suggestions to improve help-seeker's learning performances than from informal sources (e.g., previous classmates, parents) (Karabenick \& Knapp, 1991). However, the above literature has been for over than a decade. Currently, technology-supported help-seeking may strengthen motivation of help-seeking and increasingly become a social-interactive strategy (Karabenick, 2011; Puustinen, Bernicot, \& Bert-Erboul, 2011). Mäkitalo-Siegl, Kohnle and Fischer (2011) evidenced that student could acquire different help resources by the support of technology in informal learning situations. Thus, the subjects of seeking maybe vary.

Combining the social capitals for help with the types of formal/informal help-seeking, this study proposes that mentors tend to be pre-service teachers' bridging social capital, playing a role of formal helper. Mentors can help pre-service teachers develop teaching professional knowledge and transform existing teaching practices through dialogue (Crasborn, Hennissen, Brouwer, Korthagen, \& Bergen, 2010; Hiebert, Gallimore, \& Stigler, 2002). Another reason was demonstrated by Liu (2014), who evidenced that mentors often implement practice-oriented and technique-oriented supports for pre-service teachers, including teaching skills and career competitive ability rather than psychological consolation. Thus, pre-service teachers in need of professional consultation may seek help from formal sources providers (e.g, mentors, professors, administrative services), while they in need of mental consolation may seek help from intimate/close people (e.g, family members, friends, previous classmates at university) as an aforementioned bonding social capital.

Karabenick and Knapp (1991) further indicated the follow-up behaviors after help-seeking, i.e., instrumental activities (e.g., trying harder, taking better comments to perform better), lowering performance aspirations (e.g., taking a lighter study load or easier courses), and altering goals (e.g., changing to another school or major). Thus, after obtaining suggestions from helpers as well as self-reflection based on the helpers' comments, pre-service teachers may self-regulate their follow-up learning behaviors.

Self-regulation in the learning context refers to the degree of students' engagement in the learning process using meta-cognition and proper motivation (Zimmerman \& Martinez-Pons, 1988). Self-regulated learners are characterized as committed learners who efficiently control their own learning activities in many different ways which includes organizing and rehearsing learning information; monitoring their own thinking processes and seeking help; and holding positive motivational beliefs about their competence and the value of learning activities (Boekaerts, Pintrich, \& Zeidner, 2000; Schunk \& Zimmerman, 1998). Kremer-Hayon and Tillema (1999) found that pre-service teachers have a positive attitude toward self-regulated learning and high expectations about their own self-regulative competencies. Endedijk, Vermunt, Brekelmans, and Verloop (2008) investigated the way in which pre-service teachers self-regulated their learning processes in school practice and university settings by an underlying structure of two dimensions: passive versus active and prospective versus retrospective regulation of learning. Endedijk, et al., found that active regulation dominated in practice schools, while passive regulation occurred at the university. The above studies indicate that pre-service teachers have a positive characteristic toward self-regulated learning in practicum school. However, the occurrences of 
self-regulated learning of pre-service teachers depends on whether they obtain the useful information from the help-seeking subjects.

Moreover, students' self-regulated learning strategies are related to their learning self-efficacy (Pintrich \& Schunk, 2002; Wang \& Lin, 2007). Self-efficacy, involving that one can "successfully" engage in a behavior (e.g., seeking help), provides the motivational incentive to persevere when facing with problems (Bandura, 1995) Self-efficacy reflects ones' belief in their abilities to successfully acquire the help they need. That is, when pre-service teachers obtain the useful suggestions from the helper being sought, they would perceive high self-efficacy for help-seeking.

Summarily, the previous literature investigated self-efficacy for, and self-regulated learning after, help-seeking among pre-service teachers. Other studies also indicated the help-seeking subjects and potential effectiveness for students. However, fewer studies determined the relationships with the help-seeking subjects, self-efficacy for help-seeking and self-regulated learning among pre-service teachers. That is, the relationships between help-seeking subjects for pre-service teachers in need of suggestions for practicum, and their self-efficacy for help-seeking and self-regulated learning are still unclear. Thus, this present addresses the following research questions.

1. Whom do the pre-service teachers in need of suggestions for practicum seek help from?

2. Can the pre-service teachers' social capitals for help-seeking jointly predict their self-efficacy for help-seeking and self-regulated learning?

\section{Methodology}

\subsection{Research Design}

This study conducts a survey to investigate the help-seeking subjects for pre-service teachers in need of suggestions for practicum and to further determine the prediction of pre-service teachers' social capitals for help-seeking on their self-efficacy for help-seeking and self-regulated learning.

\subsection{Research Participants}

A total of 223 pre-service teachers, from a teacher education university at the middle of Taiwan, were invited to fill in the validated questionnaire in October 2015. The pre-service teachers enrolled in the filed-based practicum school distributing over the country.

\subsection{Instrument}

This study developed a questionnaire to collect the data about the help-seeking subjects of pre-service teachers, and their self-efficacy for help-seeking and self-regulated learning. The questionnaire consisted of the three sections. The original items were developed in Chinese, and latter were translated into English for submission.

The first section, baseline data, contained gender, the type of practicum school with field-based experiences, and the help-seeking subjects (i.e., family members, university professors, faculties in practicum school, classmates at university, and peer interns in practicum school). The column in each subject for help-seeking was required to choose whether to seek help during practicum (yes/no). A total of five columns were designed for the five subjects of help-seeking.

The second section was self-efficacy for help-seeking. The items of this scale referred to the perspective of self-efficacy belief by Pintrich and Schunk (2002). According to Pintrich and Schunk, the self-efficacy belief assumes that a judgment of capability to perform specific actions in light of specific goals. In this study, the self-efficacy for help-seeking scale, consisting of 3 items, reflected the self-perceptions of competence in need of help-seeking for pre-service teachers. An example item on self-efficacy for help-seeking scale was "I know who can give me useful suggestions before help-seeking."

The third section was self-regulated learning. In addition to the definition of self-regulation by literature (Boekaerts, Pintrich, \& Zeidner, 2000; Schunk \& Zimmerman,1998), the items of this scale were based on an instrument measuring self-regulated learning strategy developed by Chen and Liu (2008), who identified two facets of self-regulated learning, consisting of strategy use (cognition, motivation/affect, time, tasks) and strategy stages (forethought, monitoring, control, reaction/reflection ). A total of 16 items was in this scale. An example item on self-regulated learning scale was "After I obtain certain suggestions for problem-solving, I know which methods can let me learn better."

Responses to each item in the second and the third section were provided on a 5-point Likert scale ranging from 1 (strongly disagree) to 5 (strongly agree). All items were repeatedly revised by three professors with relevant 
expertise. Item analysis, correlation analysis, and factor analysis were conducted for instrument validity. Cronbach's alpha was initially calculated to assess the internal consistency and reliability of the sections. The calculated results of the items in the scales of self-efficacy for help-seeking, and self-regulated learning reveal Table 1.

Table 1 . Summary of validity and reliability of the study instruments

\begin{tabular}{|c|c|c|c|c|c|c|c|}
\hline \multirow{2}{*}{ section } & \multicolumn{2}{|c|}{ analysis } & \multirow{2}{*}{$\mathrm{KMO}$} & \multirow{2}{*}{$\begin{array}{l}\text { Bartlett's Test } \\
\text { of Sphericity }\end{array}$} & \multirow{2}{*}{ deleted } & \multirow{2}{*}{$\begin{array}{l}\text { Accounted } \\
\text { for }(\%)\end{array}$} & \multirow{2}{*}{$\begin{array}{c}\text { Cronbach's } \\
\alpha\end{array}$} \\
\hline & item & Coeff. & & & & & \\
\hline $\begin{array}{l}\text { Self-efficacy for } \\
\text { seeking help }\end{array}$ & $\begin{array}{c}p<.05 \\
\text { for each }\end{array}$ & $\begin{array}{c}r>.4 \text { for } \\
\text { each }\end{array}$ & 0.725 & $\begin{array}{c}\chi^{2}=260.097 \\
(p<.05)\end{array}$ & nothing & 75 & .837 \\
\hline $\begin{array}{l}\text { Self-regulation } \\
\text { after help }\end{array}$ & $\begin{array}{l}p<.05 \\
\text { for each }\end{array}$ & $\begin{array}{c}r>.4 \text { for } \\
\text { each }\end{array}$ & 0.952 & $\begin{array}{c}\chi^{2}=2029.806 \\
(p<.05)\end{array}$ & $\begin{array}{c}\text { No. } 14 \\
\text { (loading }<.4 \text { ) }\end{array}$ & 53 & .940 \\
\hline
\end{tabular}

\subsection{Data Analysis}

Data were analyzed using Chi-square Test (goodness of fit test) to investigate the help-seeking subjects for pre-service teachers in need of suggestions for practicum. By multiple regression analysis with dummy variables $(0=$ no, $1=$ yes $)$ from the subject choice as the predictor, this study identifies the prediction of pre-service teachers' social capitals for help-seeking on self-efficacy for help-seeking and self-regulated learning.

\section{Results and Discussion}

The participants, consisting of 71 males (31.8\%) and 152 females (68.2\%), enrolled in practicum at senior high school $(65,29.1 \%)$, at vocational high school $(28,12.6 \%)$, at junior high school $(128,57.4 \%)$ and at special education school $(2,0.9 \%)$.

\subsection{Help-seeking from Different Social Capitals}

The analytical results of this study by Chi-square Test achieve the significant differences in the five types of help-seeking subjects, family members $\left(\chi^{2}=4.309, \mathrm{p}<.05\right)$, university professors $\left(\chi^{2}=55.251, \mathrm{p}<.05\right)$, faculties in practicum school $\left(\chi^{2}=4.309, \mathrm{p}<.05\right)$, classmates at university $\left(\chi^{2}=102.247, \mathrm{p}<.05\right)$, and peer interns in practicum school $\left(\chi^{2}=63.502, \mathrm{p}<.05\right)$. In terms of number of the help-seeking subjects, the pre-service teachers prefer help-seeking from family members, faculties in practicum school, classmates at university and peer interns in practicum school to university professors.

Table 2. The summary of analytical results on the help-seeking subjects

\begin{tabular}{|c|c|c|c|c|}
\hline \multirow{2}{*}{ Help-seeking subjects } & \multirow{2}{*}{\multicolumn{2}{|c|}{ Number of help-seeking }} & \multicolumn{2}{|c|}{ Goodness of fit test } \\
\hline & & & $\chi^{2}$ & $p$ \\
\hline \multirow{2}{*}{ Family members } & did & 127 & \multirow{2}{*}{4.309} & \multirow{2}{*}{.038} \\
\hline & did not & 96 & & \\
\hline \multirow{2}{*}{ University professors } & did & 56 & \multirow{2}{*}{55.251} & \multirow{2}{*}{.000} \\
\hline & did not & 167 & & \\
\hline \multirow{2}{*}{ Faculties in practicum school } & did & 127 & \multirow{2}{*}{4.309} & \multirow{2}{*}{.038} \\
\hline & did not & 96 & & \\
\hline \multirow{2}{*}{ Classmates at university } & did & 187 & \multirow{2}{*}{102.247} & \multirow{2}{*}{.000} \\
\hline & did not & 36 & & \\
\hline \multirow{2}{*}{ Peer interns in practicum school } & $\operatorname{did}$ & 171 & \multirow{2}{*}{63.502} & \multirow{2}{*}{.000} \\
\hline & did not & 52 & & \\
\hline
\end{tabular}


In this study, family members and previous classmates at university belong to bridging social capital, compared to university professors, faculties and peer interns in practicum school tend to be bonding social capital. However, according to the analytical results of this study, the majority of help-seeking subjects of pre-service teachers include bridging social capital (faculties) and bonding social capital (family members, classmates at university and peer interns in practicum school). In terms of field-based school experiences, the pre-service teachers may experience task failure and emotional frustration. Literature has indicated that mentor teachers failed in finding an adequate combination of offering emotional support and task assistance for pre-service teachers (Crasborn \& Hennissen, 2010), also may lack sufficient consulting competence (Rodgers \& Keil, 2007), and seldom used emotional supports (Liu, 2014). That is, this study identifies that the help-seeking subjects of pre-service teachers include bonding and bridging social capital. Furthermore, this study also stress the importance of building both of bridging social capital and bonding social capital for pre-service teachers because the practicum school may be unable to provide emotional supports.

Notably, the number of the pre-service teachers who did not seek help from university professors is fewer than those who did. According to the literature review, the professors at teacher education institute have not sufficient school practical knowledge and cannot provide pre-service teachers with enough information for problem-solving. Additionally, the professors are not categorized to intimate/close friends and are not expected to provide emotional supports. Thus, the pre-service teachers do not consider university professors as an adequate subject of help-seeking.

\subsection{Prediction on Social Capital}

Another finding of this study is that the analytical results of multiple regression analysis achieve significant effects. In Table 3, the scores of help-seeking from faculties in practicum school and peer interns in practicum school can jointly predict self-efficacy for help-seeking $(F=4.426, p<.05)$. As for the results of self-regulated learning analysis, as the same as the analytical results of self-efficacy for help-seeking, the scores of help-seeking from faculties in practicum school and peer interns in practicum school can jointly predict self-regulation for help-seeking $(F=3.785, p<.05)$. The proportion of variance explained by the regression model is reflected by $r^{2}$ values of $7.2 \%$ for "self-efficacy for help-seeking," and $5.9 \%$ for "self-regulated learning". That is, the pre-service teachers perceive the efficacy in judgments of capability to perform specific actions and adjust learning methods after receiving useful suggestions after help-seeking from faculties in practicum school and peer interns in practicum school.

Table 3. The summary of analytical results for prediction of social capitals on self-efficacy for help-seeking and self-regulated learning

\begin{tabular}{lccccc}
\hline Predictor & $\beta$ & $t$ & $p$ & $F$ & $r^{2}$ \\
\hline Self-efficacy for help-seeking & & & & & \\
$\quad$ Family members & .029 & .441 & .660 & & \\
$\quad-.013$ & -.191 & .848 & & \\
$\quad$ University professors & .204 & 3.063 & $\mathbf{. 0 0 2}$ & $4.426^{*}$ & $7.2 \%$ \\
$\quad$ Faculties in practicum school & .086 & 1.303 & .194 & & \\
Classmates at university & .213 & 3.270 & $\mathbf{. 0 0 1}$ & & \\
$\quad$ Peer interns in practicum school & & & & & \\
Self-regulated learning & .013 & .204 & .838 & & \\
$\quad$ Family members & -.017 & -.254 & .800 & & \\
$\quad$ University professors & .153 & 2.273 & $\mathbf{. 0 2 4}$ & $3.785^{*}$ & \\
$\quad$ Faculties in practicum school & .123 & 1.854 & .065 & & \\
$\quad$ Classmates at university & .208 & 3.175 & $\mathbf{. 0 0 2}$ & & \\
$\quad$ Peer interns in practicum school & & & & & \\
${ }^{*} p<.05$ & &
\end{tabular}

As mentioned, self-efficacy reflects ones' belief in their abilities to successfully acquire the help that they need. According to the analytical results of self-efficacy for help-seeking, the pre-service teachers may obtain the 
specific suggestions by discussing with faculties in practicum school. Additionally, the pre-service teachers and their peer interns are in the same practicum school; therefore, they can collectively discuss the strategies of problem-solving. This study reveals that the scores of help-seeking from faculties in practicum school and peer interns in practicum school can "jointly" predict self-efficacy for help-seeking. That is, when the pre-service teachers could obtain the suggestions from faculties in the practicum school, they may discuss the specific details of the suggestions for problem-solving with peer interns. Another potential is that the pre-service teachers could obtain emotional supports from peer interns when facing frustration. Thus, the pre-service teachers perceive their abilities to successfully acquire the help for problem-solving. This is the reason why help-seeking from faculties as well as peer interns in practicum school can predict self-efficacy for help-seeking for pre-service teachers.

Moreover, according to the aforementioned literature in this study (Boekaerts, Pintrich, \& Zeidner, 2000; Schunk \& Zimmerman, 1998), self-regulated learners could efficiently control their own learning activities by organizing and rehearsing learning information; monitoring their own thinking processes and seeking help; and holding positive motivational beliefs about their competence and the value of learning activities. Additionally, pre-service teachers have a positive characteristic toward self-regulated learning in practicum school. The pre-service teachers could seek help from faculties in the practicum school for obtaining useful suggestions when confronting sudden problems. They may further discuss with peer interns in practicum school on the follow-up learning activities. Afterward, they may adjust their own learning activities for promoting their teaching profession. Thus, it is reasonable that the scores of help-seeking from faculties in practicum school and peer interns in practicum school can jointly predict self-regulated learning for pre-service teachers.

In sum, this study indicates a tendency. Pre-service teachers perceive the benefits of help-seeking on useful suggestions for practicum as seeking help from faculties and peer interns in practicum schools. Interestingly, peer interns in practicum school are considered as bonding social capital but maybe play a role of suggestion-provider, similar to faculties in practicum school (bridging social capital). A potential factor is that peer interns could not only give emotional supports, but also are the practice-oriented and technique-oriented supporters in field-based school experiences.

\section{Conclusion}

This study aims to investigate the help-seeking subjects for pre-service teachers in need of suggestions for practicum and to determine the prediction of pre-service teachers' social capitals for help-seeking on their self-efficacy for help-seeking and self-regulated learning. This study concludes that the pre-service teachers prefer help-seeking from family members, faculties in practicum school, classmates at university and peer interns in practicum school to university professors. Moreover, pre-service teachers perceive self-efficacy for help-seeking and self-regulated learning when seeking help from faculties and peer interns in practicum schools. That is, pre-service teachers perceive the benefits of help-seeking from faculties and peer interns in practicum schools. Notably, peer interns maybe play a role in both suggestion-providers and emotional supporters.

\section{Implications}

The study contributes to the literature by specifically revealing that pre-service teachers perceived the benefits of help-seeking in useful suggestions of teaching practices when seeking for faculties and peer interns in practicum schools. Notably, peer interns, belonging to both bonding social capital and bridging social capital, are the vital subjects of help-seeking during practicum. The collaboration among pre-service teachers would be a valued learning activity. Furthermore, online collaboration with experience sharing among pre-service teachers around the country may also be a potential strategy for pre-service teacher education.

Moreover, this study found that the pre-service teachers did not consider university professors as an adequate subject of help-seeking. Future studies could explore the roles of professors in field-based school experiences.

\section{Acknowledgments}

The research is financed by Ministry of Science and Technology, Taiwan. No. MOST-104-2410-H-018-013-SSS.

\section{References}

Bandura, A. (1995). Self-efficacy in changing societies. New York: Cambridge University Press. http://dx.doi.org/10.1017/CBO9780511527692

Boekaerts, M., Pintrich, P. R., \& Zeidner, M. (Eds.). (2000). Handbook of self-regulation. San Diego: Academic.

Bullough, R. V., \& Draper, R. J. (2004). Making sense of the failed triad: Mentors, university supervisors, and positioning theory. Journal of Teacher Education, 55(5), 407-420. http://dx.doi.org/10.1177/0022487104 269804 
Chen, C-H., \& Lin, C-W. (2008). The development of the self-regulated learning strategy inventory for junior high school students. The Archive of Guidance \& Counseling (Taiwan), 30(2), 1-36.

Crasborn, F., \& Hennissen, P. (2010). The skilled mentor: Mentor teachers' use and acquisition of supervisory skills. Eindhoven: Eindhoven School of Education.

Graham, B. (2006). Conditions for successful field experiences: Perceptions of cooperating teachers. Teaching and Teacher Education, 22(8), 1118-1129. http://dx.doi.org/10.1016/j.tate.2006.07.007

Granovetter, M. (1983). The strength of weak ties: A network theory revisited. Sociological Theory, 1, 201-233. http://dx.doi.org/10.2307/202051

Hiebert, J., Gallimore, R., \& Stigler, J. (2002). A knowledge base for the teaching profession: What would it look like and how can we get one? Educational Researcher, 31(5), 3-15. http://dx.doi.org/10.3102/0013189X 031005003

Huang, S-Y. L., \& Waxman, H. C. (2009). The association of school environment to student teachers' satisfaction and teaching commitment. Teaching and Teacher Education, 25(2), 235-243. http://dx.doi.org/10.1016/j.tate. 2008.07.015

Karabenick, S. A. (1998). Strategic help seeking: Implications for learning and teaching. Mahwah, NJ: Erlbaum.

Karabenick, S. A. (2011). Classroom and technology-supported help seeking: The need for converging research paradigms. Learning and Instruction, 21(2), 290-296. http:// dx.doi.org/10.1016/j.learninstruc.2010.07.007

Karabenick, S. A., \& Knapp, J. R. (1991). Relationship of academic help seeking to the use of learning strategies and other instrumental achievement behavior in college students. Journal of Educational Psychology, 83, 221-230. http://dx.doi.org/10.1037/0022-0663.83.2.221

Kremer-Hayon, L., \& Tillema, H. H. (1999). Self-regulated learning in the context of teacher education. Teaching and Teacher Education, 15, 507-522. http://dx.doi.org/10.1016/S0742-051X(99)00008-6

Leavey, G., Rothi, D., \& Paul, R. (2011). Trust, autonomy and relationships: The help-seeking preferences of young people in secondary level schools in London (UK). Journal of Adolescence, 34, 685-693. http://dx.doi.org/10.1016/j.adolescence.2010.09.004.

Lindsey, M. A., Joe, S., \& Nebbitt, V. (2010). Family matters: The role of mental health stigma and social support on depressive symptoms and subsequent help seeking among African American boys. The Journal of Black Psychology, 36, 458-482. http://dx.doi.org/10.1177/0095798409355796.

Mäkitalo-Siegl, K., Kohnle, C., \& Fischer, F. (2011). Computer-supported collaborative inquiry learning and classroom scripts: Effects on help-seeking processes and learning outcomes. Learning and Instruction, 21(2), 257-266. http://dx.doi.org/10.1016/j.learninstruc.2010.07.001

Malecki, C. K., \& Demaray, M. K. (2003). What type of support do they need? Investigating student adjustment as related to emotional, informational, appraisal, and instrumental support. School Psychology Quarterly, 18, 231-252. http://dx.doi.org/10.1521/scpq.18.3.231.22576

Marable, M., \& Raimondi, S. (2007). Teachers' perceptions of what was most (and least) supportive during their first year of teaching. Mentoring \& Tutoring: Partnership in Learning, 15, 25-37. http://dx.doi.org/10.1080/13611260601037355

Newman, R. S., \& Goldin, L. (1990). Children_s reluctance to seek help with schoolwork. Journal of Educational Psychology, 82, 92-100. http://dx.doi.org/10.1037/0022-0663.82.1.92

Pintrich, P. R., \& Schunk, D. H. (2002). Motivation in education: Theory, research, and applications (2nd ed.). New Jersey: Prentice Hall.

Putnam, R. D. (2000). Bowling alone: The collapse and revival of American community. New York: Simon \& Schuster. http://dx.doi.org/10.1145/358916.361990

Puustinen, M., Bernicot, J., \& Bert-Erboul, A. (2011). Written computer mediated requests for help by French-speaking students: an analysis of their forms and functions. Learning and Instruction, 21(2), 281-289. http://dx.doi.org/10.1016/j.learninstruc.2010.07.005

Rippon, J. H., \& Martin, M. (2006). What makes a good induction supporter? Teaching and Teacher Education, 22, 84-99. http://dx.doi.org/10.1016/j.tate.2005.07.004

Rodgers, A., \& Keil, V. (2007). Restructuring a traditional student teacher supervision model: Fostering enhanced professional development and mentoring within a professional development school context. 
Teaching and Teacher Education, 23(1), 63-80. http://dx.doi.org/10.1016/j.tate.2006.04.012

Ryan, A., Pintrich, P., \& Midgley, C. (2001). Avoiding seeking help in the classroom: Who and why? Educational Psychology Review, 13(2), 93-114. http://dx.doi.org/10.1023/a:1009013420053.

Sariçoban., A. (2010). Problems encountered by student-teachers during their practicum studies. ProcediaSocial and Behavioral Sciences, 2, 707-711. http://dx.doi.org/10.1016/j.sbspro.2010.03.088

Schunk, D. H., \& Zimmerman, B. J. (Eds.). (1998). Self-regulated learning: From teaching to self-reflective practice. New York: The Guilford Press.

Veeman, S. (1984). Perceived problems of beginning teachers. Review of Educational Research, 54(2), 143-178. http://dx.doi.org/10.3102/00346543054002143

Wang, S. L., \& Lin, S. J. (2007). The application of social cognitive theory to web-based learning through NetPorts. British Journal of Educational Technology, 38(4), 600-612. http://dx.doi.org/10.1111/j.1467-8535. 2006.00645.x

Wenz-Gross, M., \& Siperstein, G. N. (1998). Students with learning problems at risk in middle school: Stress, social support, and adjustment. Exceptional Children, 65, 91-100.

Williams, D. (2006). On and off the Net: Scales for social capital in an online era. Journal of Computer-Mediated Communication, 11(2), 593-628. http://dx.doi.org/10.1111/j.1083-6101.2006.00029.x

Zimmerman, B. J., \& Martinez-Pons, M. (1988). Construct validation of a strategy model of student self-regulated learning. Journal of Educational Psychology, 80, 284-290. http://dx.doi.org/10.1037/00220663.80.3.284

\section{Copyrights}

Copyright for this article is retained by the author(s), with first publication rights granted to the journal.

This is an open-access article distributed under the terms and conditions of the Creative Commons Attribution license (http://creativecommons.org/licenses/by/3.0/). 